\title{
RESEARCH
}

\section{THE INVESTIGATION OF THE USE OF EMERGENCY MEDICAL SERVICES FOR GERIATRIC PATIENTS DUE TO SUICIDE}

Turkish Journal of Geriatrics

DOI: 10.31086/tigeri.2020.141

2020; 23(1): 82-89

\section{- Selvi KAYIPMAZ1 1 D \\ - Semih KORKUT ${ }^{2}$ iD \\ . Eren USUL ${ }^{3}$ (D)}

CORRESPONDANCE

Selvi KAYIPMAZ

Baskent University Faculty of Medicine,

Department of Psychiatry, Ankara, TURKEY

Phone: +905062849610

e-mail: selviceran@hotmail.com

Received: 27/11/2019

Accepted: 06/01/2020

${ }^{1}$ Baskent University Faculty of Medicine,

Department of Psychiatry, Ankara, TURKEY.

2 Ministry of Health of Turkey, General Director

of Emergency Medical Services, Ankara,

TURKEY.

${ }^{3}$ Provincial Health Directorate of Ankara, Deputy Director of Emergency Medical Services,

Ankara, TURKEY.

\section{A}

Introduction: Ageing is a physiological process, and inevitable psychological and physical changes occur after the age of 65 in every individual. Elderly suicide is a crucial public health concern that is still largely ignored worldwide. The purpose of this study is to investigate the use of emergency medical services by geriatric patients due to suicide.

Materials and Method: We obtained the demographic and clinical information of the patients from the records. We retrospectively examined the data of all patients, who are 65 and older, enrolled in Turkey for the suicide attempt between September 2018 and August 2019.

Results: Our study included 769 cases. There was a statistically significant difference between the two genders in terms of the number of completed suicides ( $p$ $<0.001)$. The most common suicide method was drug use (30.8\%). In total, $36.7 \%$ of women and $62.7 \%$ of men used violent methods for suicide. We found a statistically significant difference between the groups in terms of violent method usage ( $p$ $<0.001)$. There was a statistically significant difference between the age groups in terms of completed suicide percentages $(p=0.008)$, and the cases reported from urban and rural areas in terms of mortality $(p<0.001)$.

Conclusion: The percentage of completed suicides increases with age, and the careful evaluation of suicide attempts is vital in reducing the risk of suicide-related death. The process starting from the moment of notification of suicide attempt to the emergency dispatch centre must be managed effectively and quickly by trained and experienced medical teams.

Key words: Emergency Treatment; Health Services for the Aged; Suicide. 


\section{INTRODUCTION}

Ageing is a physiological process, and inevitable psychological and physical changes occur after the age of 65 in every individual who successively reaches this age. According to the World Health Organization's old age report published in 2015, the elderly population in the world is expected to grow twice its present size in 2050. Therefore, interventions aiming at improving the geriatric health in the future health policies of the countries are highly recommended. Elderly suicide is a crucial public health concern that is still largely ignored worldwide. Suicide rates have been reported to be higher among the elderly in all the countries. The highest rate of suicide was reported in the individuals who were 70 years and older. (1-3)

Pre-hospital emergency medical services (EMS) are known to be the first medical contact with the patients who are at a risk of suicide, especially in the rural areas. (4) A study conducted in Valencia reported that 6,537 suicide-related emergency calls were received over the course of 7 years, of which 142 were completed suicides. (5) However, it is stated that suicide attempts are under-reported, even in countries with an advanced registration system. It is also reported that the cases treated by emergency health services are often more critical.

(6) Considering that some of the suicide-related emergency calls are also refused to be taken to the hospital, the notifications made to the emergency dispatch centres provide reliable data on suicide attempts. (7) The fact that EMS providers receive adequate training on this issue is also considered as a crucial point in terms of preventing suicides. (4)

In our knowledge, although various studies have been published in some of the provinces and territories of our country for the use of EMS for suicide-related emergencies, a study reflecting the general state has not been published yet. Therefore, the purpose of this study is to investigate the use of EMS by geriatric patients due to suicide. By examining the pre-hospital records, we aimed to reveal not only the completed suicides but also the data on all suicide attempts reported to the emergency dispatch centres. Thus, we also aimed to contribute to the planning of preventive and therapeutic health services to be provided to the geriatric individuals in the vulnerable and disadvantaged group for suicide.

\section{MATERIALS AND METHOD}

This study is designed as a cross-sectional epidemiological study. After obtaining the approval of Başkent University Medical and Health Sciences Research Board (project no: KA19/318), we applied to the Ministry of Health for permission. After receiving the necessary permission, we obtained the demographic and clinical information of the patients from the records of the Emergency Health Automation System (ASOS). We retrospectively examined the data of all patients, who are 65 and older, enrolled in Turkey for the suicide attempt between September 2018 and August 2019. We recorded the date, month, season, time, the ruralurban distinction and the provinces from which the calls were made to the emergency dispatch centres by the patients. We determined the age, age group, gender, on-site mortality and suicide methods of the patients. The use of drugs, chemicals or natural gas and jumping into the water were considered as the cases of non-violent suicide, whereas the use of a sharp or blunt object and firearms, self-hanging, jumping in front of a moving motor vehicle (car or train, etc.), jumping from high places and self-immolation were considered as the cases of violent suicide. (8)

We conducted our study on the 769 calls made due to suicide between the dates mentioned above.

\section{Statistical Analysis}

We evaluated whether the data showed a normal distribution with the help of graph and Kolmogorov-Smirnov test. We presented descriptive statistics as number (n), percentage (\%), median and interquartile range. The Mann-Whitney $U$ test was employed to assess the numerical data, which 
did not fit the normal distribution in the paired group comparisons, whereas the Chi-square test was employed to assess the categorical data. Patients were divided into three groups according to their ages: 65-74 years (young-old), 75-84 years (middle-old) and 85 years and older (oldest-old) as described by Koo et al. (9) $p<0.05$ was considered statistically significant.

\section{RESULTS}

Our study included 769 cases of patients, who are 65 years and over and have a history of suicide attempts or completed suicide between 01.09.2018 and 31.08.2019 in Turkey. In total, 34.5\% ( $n=265)$ of the cases were female. The median age of the total cohort was 72 (11) years. The median age of the females was 71 (11) years, whereas the median age of the males was 72 (11) years. We did not find any statistically significant difference between the female and male groups in terms of age $(p=0.812)$.

We divided the patients into three groups. Accordingly, there were 472 patients $(61.4 \%)$ in the 65-74 age group, 217 patients (28.2\%) in the 7584 age group and 80 patients (10.4\%) aged in the group of 85 years and older.
Of these, $54.7 \%(n=421)$ of these cases were reported between 8.00 and 15.59 hours, 32.6\% ( $n=$ 251) were reported between 16.00 and 23.59 hours and $12.6 \%(n=97)$ were reported between 00.00 and 07.59 hours. The seasonal distribution of cases was as follows: summer had $31.1 \%(n=239)$, autumn had $22 \%(n=169)$, winter had $20.8 \%(n=160)$ and spring $26.1 \%$ of the cases ( $n=201)$.

In total, $68.9 \%$ ( $n=530$ ) of the cases were reported from the urban areas, whereas the rural areas reported $31.1 \%(n=239)$ of the cases. The distribution of cases by seven geographical regions of Turkey is presented in Table 1. Most of the cases were reported from the Marmara region (26.9\%), which is the most crowded geographical region of Turkey.

In total, $68.9 \%$ ( $n=530$ ) of the cases were suicide attempts, whereas $31.1 \%(n=239)$ of these cases were completed suicides. In other words, $31.1 \%$ of the cases lost their lives.

Table 2 shows the comparison of completed suicide and attempted suicide cases by gender. There was a statistically significant difference between the two genders in terms of the number of completed suicides ( $p<0.001)$. In total, $37.1 \%$ of suicides in males were completed suicides.

Table 1. Distribution of suicide cases aged 65 and over by seven geographical regions of Turkey.

\begin{tabular}{|l|r|r|}
\hline Geographical Region & Number & \% \\
\hline Marmara & 207 & 26.9 \\
\hline Aegean & 184 & 23.9 \\
\hline Mediterranean & 99 & 12.9 \\
\hline Central Anatolian & 124 & 16.1 \\
\hline Black Sea & 94 & 12.2 \\
\hline Eastern Anatolian & 40 & 5.2 \\
\hline Southeastern Anatolian & 21 & 2.7 \\
\hline Total & 769 & 100 \\
\hline
\end{tabular}


Table 2. Distribution of suicide attempts and completed suicide cases by gender.

\begin{tabular}{|l|r|r|r|c|}
\hline Gender & $\begin{array}{r}\text { Suicide } \\
\text { attempts }\end{array}$ & $\begin{array}{r}\text { Completed } \\
\text { suicides }\end{array}$ & Total & p value \\
\hline Female & $213(80.4 \%)$ & $52(19.6 \%)$ & $265(100 \%)$ & $<0.001 *$ \\
\hline Male & $317(62.9 \%)$ & $187(37.1 \%)$ & $504(100 \%)$ & \\
\hline Total & $530(68.9 \%)$ & $239(31.1 \%)$ & $769(100 \%)$ & \\
\hline
\end{tabular}

*Chi-square test

Table 3. Distribution of cases by suicide methods.

\begin{tabular}{|c|c|c|c|c|c|}
\hline \multirow[b]{2}{*}{ Suicide methods } & \multicolumn{2}{|c|}{ Gender n (\%) } & \multicolumn{2}{|c|}{ Mortality n (\%) } & \multirow{2}{*}{$\begin{array}{r}\text { Total } n \\
(\%)\end{array}$} \\
\hline & Female & Male & $\begin{array}{l}\text { Non- } \\
\text { survivor }\end{array}$ & Survivor & \\
\hline Drug use & $120(45.3)$ & $117(23.2)$ & $0(0)$ & $237(100)$ & 237(30.8) \\
\hline Chemical use & $30(11.3)$ & $42(8.3)$ & $1(1.4)$ & $71(98.6)$ & $72(9.4)$ \\
\hline Sharp or blunt object & $10(3.8)$ & $46(9.1)$ & $3(5.4)$ & $53(94.6)$ & $56(7.3)$ \\
\hline Self-hanging & $53(20)$ & $142(28.2)$ & $157(80.5)$ & $38(19.5)$ & 195(25.4) \\
\hline Firearms & $1(0.4)$ & $75(14.9)$ & $57(75)$ & $19(25)$ & $76(9.9)$ \\
\hline $\begin{array}{l}\text { Jump in front of a moving motor vehicle (car-train, } \\
\text { etc.) }\end{array}$ & $2(0.8)$ & $3(0.6)$ & $2(40)$ & $3(60)$ & $5(0.7)$ \\
\hline Jumping from high places & $20(7.5)$ & $23(4.6)$ & $13(30.2)$ & $30(68.8)$ & $43(5.6)$ \\
\hline Natural gas & $1(0.4)$ & $5(1)$ & $2(33.3)$ & $4(66.7)$ & $6(0.8)$ \\
\hline Burning himself/herself & $2(0.8)$ & $1(0.2)$ & $1(33.3)$ & $2(66.7)$ & $3(0.4)$ \\
\hline Jumping into water & $2(0.8)$ & $3(0.6)$ & $0(0)$ & $5(100)$ & $5(0.7)$ \\
\hline Drugs + chemicals & $2(0.8)$ & $8(1.6)$ & $\mathrm{O}(0)$ & $10(100)$ & $10(1.3)$ \\
\hline Drug use + sharp or blunt object & $0(0)$ & $1(0.2)$ & $\mathrm{O}(0)$ & $1(100)$ & $1(0.1)$ \\
\hline Chemical use + sharp or blunt object & $2(0.8)$ & $2(0.4)$ & $\mathrm{O}(0)$ & $4(100)$ & $4(0.5)$ \\
\hline Self-hanging + jumping from high places & $0(0)$ & $1(0.2)$ & $0(0)$ & $1(100)$ & $1(0.1)$ \\
\hline Others & $20(7.5)$ & $35(6.9)$ & $3(5.5)$ & $52(94.5)$ & $55(7.2)$ \\
\hline Total & $265(100)$ & $504(100)$ & $239(31)$ & $530(68.9)$ & $769(100)$ \\
\hline
\end{tabular}

*n: number

Table 3 summarizes the cases according to the suicide methods. According to the observations, the most common suicide method was drug use (30.8\%). This was followed by suicides done by self-hanging (25.4\%) and using firearms (9.9\%). The most common suicide method in women was drug use with $45.3 \%$, whereas the most common method was self-hanging in men (28.2\%). In total, $36.7 \%$ of women $(n=90)$ and $62.7 \%$ of men $(n=294)$ used violent methods for suicide. By comparing the two 
Table 4. The mortality according to age groups.

\begin{tabular}{|r|r|r|r|r|}
\hline Age group & $\begin{array}{r}\text { Completed } \\
\text { suicides }\end{array}$ & Suicide attempts & Total & p value \\
\hline $65-74$ years & $132(28 \%)$ & $340(72 \%)$ & $472(100 \%)$ & 0.008 \\
\hline $75-84$ years & $71(32.7 \%)$ & $146(67.3 \%)$ & $217(100 \%)$ & \\
\hline 85 years and older & $36(45 \%)$ & $44(55 \%)$ & $80(100 \%)$ & \\
\hline Total & $239(31.1 \%)$ & $530(68.9 \%)$ & $769(100 \%)$ & \\
\hline
\end{tabular}

groups, we found a statistically significant difference between the groups in terms of violent method usage $(p<0.001)$.

Table 4 shows the mortality according to age groups. Accordingly, there was a statistically significant difference between the age groups in terms of completed suicide percentages $(p=0.008)$. We used paired group comparisons by employing Bonferroni correction to determine which groups stem from the difference. We found that the difference was between the age groups of 65-74 and 85 years and older $(p=0.002)$.

The mortality rates in urban and rural areas were $24.2 \%$ and $46.4 \%$, respectively. There was a statistically significant difference between the cases reported from urban and rural areas in terms of mortality $(p<0.001)$.

\section{DISCUSSION}

The results of our study revealed the characteristics of suicide attempts and completed suicides of geriatric individuals in our country. Accordingly, the ratio of completed suicides to suicide attempts was $1: 2.2$. The suicide attempts were higher in the males (65.5\%). Besides, the number of completed suicides was significantly higher in men than in women ( $p$ <0.001). In our country, Ozer et al. reported a higher percentage $(74.5 \%)$ of men committing suicide than women in a study of completed suicides of geriatric population. (10) In 2018, the Turkey Statistical Institute has announced that the number of suicides by males in the general population was higher than women (2391 vs. 770). (11) Our results are consistent with the literature. In addition, the suicide rates in men in the geriatric age group were reported to be higher than the general age group. (12) In the general population, unlike our study, suicide attempts were higher in the females. (13)

The suicide rates in the geriatric age group are reported to be highest in the age group of 75 years and over. (12) Our study determined most of the cases of suicide $(61.4 \%)$ in 65-74 years group. Besides, the completed suicide proportion was the lowest in this group (28\%). This proportion was the highest in 85 years and older group (45\%).

A study, which evaluated the suicide attempts in all the age groups in Sanliurfa, Turkey, found that nearly half of the cases $(49.8 \%)$ occurred between 16.00 and 24.00 hours. (14) In our study, cases were concentrated between 08.00 and 16.00 (54.7\%). We believe that this difference is because all the mentioned cases in the first study were under 65 years of age. From this observation, we can conclude that the cases in the geriatric age group are intensified when the family members are not at home.

Akkaya-Kalayci et al. found that the suicide attempts were most common in summer $(30.6 \%)$ in Istanbul. They examined suicide attempts of young individuals between the ages of 15 and 25. (15) In 
our study, although the ages of the cases were a lot different from this study, suicides were most common in summer (31.1\%). A study conducted by Nazari Kangavari et al in Iran showed that the number of completed suicides was higher in the months of summer. (16)

Senol et al. reported that $65.5 \%$ of the patients who applied to the emergency department for suicide chose using drugs as a suicide method. (17) Dilbaz et al. showed that the most commonly used suicide methods were excessive use of drug, chemicals or sharp objects, self-hanging, jumping from high places, and killing self by a firearm. (18) The most common suicide methods reported in our study were drug use, self-hanging and killing self by firearms. Violent (62.7\%) and completed suicides (37.1\%) were more common in men, and the most common methods were self-hanging, drug use and killing self by firearms. Ozer et al. found that self-hanging was the most common method in the completed suicides among geriatric population. (10) Besides, violent methods were reported to be used more frequently by males as shown in our study. (12)

In our study, we found that most suicides (68.9\%) were reported from the urban areas, but we also found that completed suicides were considerably higher in the rural areas $(p<0.001)$. In the United States, it was found that the rates of suicide were higher in rural areas than in urban areas (20 vs. 11 per hundred thousand). (19) Although it has been suggested that the more widespread use of firearms in the rural areas may be a reason for high rates of suicides, the reasons for this situation remain unclear. (20) In our study, the most common method in completed suicides in rural areas was self-hanging ( $n=74)$, followed by killing self with a firearm $(n=30)$. In countries and states where access to firearms is not easy under the law, suicide rates were found to be less. It is stated that limiting the possession of firearms will reduce the suicide-related mortality even if it does not change the total number of suicide attempts. (12)
The strength of our study is that it includes a large sample and demographic information on both suicide attempts and completed suicides. Given the difficulties in accessing data on suicide attempts, the generalizability of our results is stronger than the previous studies that only involve a hospital emergency department or psychiatry clinics. There are some limitations in our study: the suicide attempt data of EMS are the only considered data in our study, and it does not include suicide attempt cases of people, who applied to the hospital with their means and did not apply to any other health service. There were no data on the marital status, socioeconomic information, educational status, previous physical or psychiatric diseases, suicide attempts, addictions and medications of the patients included in the study. Therefore, other risk factors reported in the previous suicide-related studies could not be analyzed. We believe that acquiring this information in future prospective studies at the national scale will be beneficial in revealing the preventable causes of suicide.

\section{CONCLUSION}

In conclusion, the completed and attempted suicide frequencies were higher in males. The drug use was the most common suicide method among geriatric individuals. The men used violent methods more than women. Most of the suicide cases were in the young-old age group. The completed suicide proportion was the highest in the oldest-old age group. The mortality rates were higher in rural areas than in urban areas.

The percentage of completed suicides increases with age, and the careful evaluation of suicide attempts is vital in reducing the risk of suicide-related death. EMS is the medical unit, which is firstly contacted by most of the geriatric patients with suicide attempts. The process starting from the moment of notification of suicide attempt to the emergency dispatch centre must be managed effectively and quickly by trained and experienced 
medical teams. (21) Taking into consideration the importance of EMS records in terms of suicide statistics and risk factors, the results of our study can be used for the planning of protective measures in this area. Further studies are needed to determine the risk factors related to geriatric suicides.

\section{REFERENCES}

1. World Health Organization? World report on ageing and health. 2015 [Internet] Available from: https:// apps.who.int/iris/handle/10665/186463. Accessed 18.11.2019.

2. Lapierre S, Erlangsen A, Waern M, et al. International Research Group for Suicide among the Elderly. A systematic review of elderly suicide prevention programs. Crisis 2011;32(2):88-9. (PMID: 21602163).

3. Värnik P. Suicide in the World. Int J Environ Res Public Health 2012;9(3):760-71. (PMID:22690161).

4. Lygnugaryte-Griksiene A, Leskauskas D, Jasinskas $\mathrm{N}$, Masiukiene A. Factors influencing the suicide intervention skills of emergency medical services providers. Med Educ Online 2017;22(1):1291869. (PMID:28235388).

5. Marco M, López-Quílez A, Conesa D, Gracia E, Lila M. Spatio-Temporal Analysis of Suicide-Related Emergency Calls. Int J Environ Res Public Health 2017;14(7):1-13. (PMID:28684714).

6. Bahia CA, Avanci JQ, Pinto LW, Minayo MCS. Selfharm throughout all life cycles: profile of victims using urgent and emergency care services in Brazilian state capitals. Cien Saude Colet 2017;22(9):2841-50. (PMID:28954135).

7. Mejías-Martín Y, Martí-García C, Rodríguez-Mejías C, Valencia-Quintero JP, García-Caro MP, Luna JD. Suicide attempts in Spain according to prehospital healthcare emergency records. PLoS One 2018;13(4):e0195370. (PMID:29630660).

8. Veisani $Y$, Delpisheh A, Sayehmiri K, Moradi G, Hassanzadeh J. Seasonality in Violent and Nonviolent Methods of Suicide Attempts: A Cross-Sectional Study on Systematic Registry Data. Acta Med Iran

\section{CONFLICT OF INTEREST}

The authors declared that there was no conflict of interest.

\section{7;55(8):507-13. (PMID:29034674).}

9. Koo YW, Kõlves K, De Leo D. Suicide in older adults: differences between the young-old, middle-old, and oldest old. Int Psychogeriatr. 2017;29(8):1297-1306.

10. Ozer E, Gumus B, Balandiz H, Kirci GS, Aydogdu HI, Tetikcok R. Evaluation of geriatric suicides in Turkey. J Forensic Leg Med 2016;44:158-61. (PMID:27810586).

11. Turkish Statistical Institute. Suicide statistics of 2018. [Internet] Available from: http://www.turkstat.gov. tr/PrelstatistikTablo.do?istab_id=106. Accessed 18.11.2019.

12. Aslan M, Hocaoglu C. Suicidal Behavior in Elderly. Current Approaches in Psychiatry 2014;6(3):294-309. (doi: 10.5455/cap.20131229101314).

13. Ozguven HD. The Epidemiology of Suicidal Behavior. Turkiye Klinikleri J Psychiatry-Special Topics 2008;1(3):1-7. [Internet] Available from: https://www. turkiyeklinikleri.com/article/tr-intihar-davranisininepidemiyolojisi-53360.html. Accessed 18.11.2019.

14. Atli A, Uysal C, Kaya MC, et al. Assessment of admission to the emergency department due to suicide attempt: Sanliurfa sample. Journal of Mood Disorders 2014;4(3):110-4. (doi: 10.5455/ jmood.20131230123128).

15. Akkaya-Kalayci T, Vyssoki B, Winkler D, et al. The effect of seasonal changes and climatic factors on suicide attempts of young people. BMC Psychiatry 2017;17(1):365. (PMID:29141599).

16. Nazari Kangavari H, Shojaei A, Hashemi Nazari SS. Suicide Mortality Trends in Four Provinces of Iran with the Highest Mortality, from 2006-2016. J Res Health Sci 2017;17(2):e00382. (PMID:28676594). 
17. Senol V, Unalan D, Avsarogullari L, Ikizceli I. An analysis of patients admitted to the Emergency Department of Erciyes University Medical School due to suicidal attempt. Anadolu Psikiyatri Derg 2005;6(1):1929. [Internet] Available from: https://trdizin.gov. $\mathrm{tr} /$ publication/show/pdf/paper/TkRZNU56YzM. Accessed 18.11.2019.

18. Dilbaz N, Sengul CB, Cetin MK, et al. Evaluation of Suicide Attempters in General Hospital. Kriz Dergisi 2005;13(2):1-10. (doi: 10.1501/Kriz_0000000223).

19. Hedegaard H, Curtin SC, Warner M. Suicide mortality in the United States, 1999-2017. US Department of Health and Human Services, Centers for Disease Control and Prevention, National Center for Health Statistics. [Internet] Available from: https://www.cdc. gov/nchs/data/databriefs/db330-h.pdf. Accessed 18.11.2019.
20. Nestadt PS, Triplett P, Fowler DR, Mojtabai R. Urban-Rural Differences in Suicide in the State of Maryland: The Role of Firearms. Am J Public Health 2017;107(10):1548-53. (PMID:28817331).

21. S Aker, $\bigcirc$ Boke, Y Peksen. Evaluation of psychiatric disorders among admittances to 112 emergency services in Samsun - 2004. Anadolu Psikiyatri Derg 2006;7(4):211-7. [Internet] Available from: https://trdizin.gov.tr/publication/paper/detail/ Tmpnd05UYzM. Accessed 18.11.2019. 